\title{
The Analysis of Argument-Counterargument Structure in Chinese EFL Learners' Argumentative Writing
}

\author{
Fangyuan Du \\ College of Foreign Languages and Literature, Fudan University \\ 220 Handan Road, Shanghai 200433, China \\ E-mail: fydu@fudan.edu.cn
}

Received: June 1, 2017 Accepted: July 28, $2017 \quad$ Published: August 1, 2017

doi:10.5296/jse.v7i3.11275 URL: https://doi.org/10.5296/jse.v7i3.11275

\begin{abstract}
This study aims to analyze argument-counterargument structure of English argumentative essays written by Chinese EFL university students, based on the adapted Toulmin's (2003) model of the argument structure constituting four elements (i.e. claim, data, counterargument and rebuttal). It also measures whether there is a correlation between the use of counterargument structure and the participants' overall essay quality assessed by an online AWE (Automated Writing Evaluation) program. Three hundred and ninety students with various majors in a Chinese university submitted their argumentative essays in English online. The results demonstrated that half of the participants developed a one-sided model of argumentation while the other half of them used argument-counterargument structure in their essays. The participants' use of counterarguments affected the overall quality of their essays. Pedagogical implications of these findings are also discussed.
\end{abstract}

Keywords: argumentative writing, argument-counterargument structure, EFL 


\section{Introduction}

Argumentation is the practice of stating claims and offering reasons to justify beliefs in order to influence others (Inch \& Warnick, 2010). While seeking reasons to support claims may be an innate human trait, argumentation in writing is a much more complicated skill requiring training and practice. Within the context of English as the first language (L1) education, the Toulmin model of argument structure, proposed by the British philosopher Toulmin $(1958,2003)$, has been widely used in teaching and researching argumentative writing. It is composed of six elements. The first four are claims, data, warrants and backing; data are facts that support the claim. The two other elements are qualifiers, which place limits on the strength of the initial claim, and rebuttals, which acknowledge that despite the careful construction of the argument, there may still be counterarguments. It is generally acknowledged that counterargument is a key feature contributing to the persuasiveness of argumentative essay because the presence of opposing views enables a writer to examine his/her opinions in response to those opposite views and to question his/her initial position (Leitao, 2000). However, recent research has revealed that students tend to neglect opposing viewpoints when responding to argumentative writing prompts in L2. Kobayashi and Rinnert (2007) found that some of their participants who did not supply a counterargument structure in the English L2 essay used this rhetorical feature in their Japanese L1 essays. Similarly, Qin and Karabacak (2010) reported the tendency of not supplying a counterargument/refutation section in the English L2 essays produced by Chinese EFL learners.

On the other hand, various automated writing evaluation (AWE) programs supported by sophisticated language processing technologies has flourished. Compared to traditional human reviewers, AWE programs had unprecedented advantages: diagnostic feedback and holistic scores on student writing (Shermis and Burstein, 2003), immediacy of online comments (Dikli, 2006) and positive effects on student autonomy (Chen \& Cheng, 2008). Based on a report from an AWE program by a Chinese company (www.pigai.org), the reliability of scores assessed by their AWE program and human reviewers on writings in a final exam of Nanjing University was $92.03 \%(\mathrm{Hu}, 2015)$. However, some scholars argued that AWE programs perform ineffectively at addressing global language concerns, including meaning, idea development, and aspects of writing that require higher-order thinking (Liao, 2016). It is well-known that argument-counterargument structure in argumentative essays is cognitively demanding and a representation of higher order thinking processes. Up to now, no study has been conducted to investigate the correlation between the argument-counterargument structure and the assessment of writing by AWE program.

This study aims to analyze counterargument elements in argumentative papers written by EFL students, and to investigate the relationship between the uses of counterargument and the overall quality of argumentative papers assessed by AWE program. The specific research questions are as follows:

1) To what extent do Chinese EFL students develop argument-counterargument structure in their English argumentative essays?

2) What is the relationship between the uses of counterargument and the overall quality of 
argumentative essays assessed by AWE program?

\section{Methods}

\subsection{Participants}

Three hundred and ninety students with various majors in a mainland Chinese comprehensive university took part in the study. They were all native Chinese speakers ranging from 18 to 22 and had been learning English for approximately ten years. They were informed of participating in an English writing competition online and were volunteered to submit their English essays within a required date.

\subsection{Procedure}

The researcher chose and selected one writing topic considering its argumentative nature. The topic was whether Chinese Spring Festival Gala should invite foreign stars or not. For details, see Appendix. It was selected based on the rationale that the participants may have been familiar with the topic, and be interested in writing about them. The participants were asked to write an argumentative essay in English about 500 words and come up with their own view on the issue.

The participants were informed that it was an English writing competition and the top three participants could participate in the national English writing competition representing the university. They were asked to write an English essay out of class and submitted it online. The researcher provides a web-based AWE program called www.pigai.org for students to submit essays online. Although it could assess an essay in three seconds, it would not show scores to participants. It was approximately three weeks for students to write their essays before the deadline. Overall, 390 essays were written by the participants.

\subsection{Data coding and scoring}

The participants' argumentative essays were analyzed in terms of the presence and absence of four Toulmin elements: claim, data, counterclaim, and rebuttal as well as their overall writing scores as rated by www.pigai.org, a Chinese automated writing evaluation program. The definitions and examples of the four Toulmin elements are presented in Table 1 (Ramage and Bean, 1999). The reason for choosing these four elements is that they have often been used in relevant studies, and have been shown to be identified relatively reliable in argumentative texts (Crammond, 1998; Knudson, 1992; McCann, 1989; Nussbaum \& Kardash, 2005). In addition, counterarguments were coded regardless of whether it belongs to counterargument claim or data. The decision was made because the focus of this study is whether participants are aware of opposing views other than their own views, and whether they can effectively refute those opposing view.

Following Crammond (1998) and Stapleton (2001), the identification of these elements was sometimes based on semantic structures and linguistic elements that typically signal their presence. For example, to identify claims, two linguistic patterns were used: (a) "I think," "In my opinion," and (b) "Without ..." To identify data, transitional words such as "because" and prepositional phrases such as "for one thing" were used. A counterargument and a rebuttal often went hand in hand. To identify them, certain indicator phrases such as "although," "even though" were found. However, it should be noted that these semantic structures and 
linguistic elements can only assist the identification process. Sometimes students only imply their positions, reasons, counterarguments, and rebuttals without using words or phrases as mentioned above. Therefore, double coding was necessary for a reliable and valid analysis. Also, we examined the essays that did not include any counterarguments as a reliability check. The results further confirmed the findings.

Table 1. Definitions and examples of four Toulmin elements (examples chosen from students' essays)

\begin{tabular}{|l|l|}
\hline Elements & Definition with Illustrative Examples \\
\hline Claim & $\begin{array}{l}\text { Definition: An assertion in response to a contentious topic or problem } \\
\text { Example: As far as I am concerned, I am in favor of the latter view due to the } \\
\text { following aspects. }\end{array}$ \\
\hline Data & $\begin{array}{l}\text { Definition: Evidence to support a claim, such as facts, statistics, anecdotes, } \\
\text { research studies, expert opinions, definitions, analogies, and logical } \\
\text { explanations } \\
\text { Example: } \\
\text { 1. First of all, the Spring Festival gala, generally considered as a symbol of } \\
\quad \text { China, ought to be our own festival showing the essence of Chinese } \\
\text { culture. } \\
\text { Also, as the most popular gala in China, the size and structure of its } \\
\text { audience should be taken into consideration. }\end{array}$ \\
\hline $\begin{array}{l}\text { Counter- } \\
\text { argument }\end{array}$ & $\begin{array}{l}\text { Definition: The possible opposing views that can challenge the validity of a } \\
\text { writers' claim } \\
\text { Example: I've heard some people argue that inviting foreign stars is a form } \\
\text { of cultural integration and good art work goes beyond boundaries. }\end{array}$ \\
\hline Rebuttal & $\begin{array}{l}\text { Definition: Statements in which the writer responds to a counterargument by } \\
\text { pointing out the possible weakness. } \\
\text { Example: There's nothing wrong in bringing foreign stars onto the stage but } \\
\text { the Spring Festival gala's stage should be excluded because the aim of this } \\
\text { gala is to show the Chinese traditional cultural treasures to people at home } \\
\text { and abroad rather than popularize exotic fashions. }\end{array}$ \\
\hline
\end{tabular}

Concerning the overall quality of the participants' argumentative essays, an AWE system developed by a Chinese technology company was introduced. It offers an online automatic grading service based on corpus and cloud computing technology. The scale evaluates four aspects: vocabulary, sentence, discourse and content. Similar to other AWE programs, it generates holistic scores, overall comments, and sentence-based evaluations. It should be mentioned that the scale did not emphasize the use of counterargument. 


\section{Results and Discussions}

\subsection{Patterns of Argument-Counterargument Structure in the Students' English Argumentative} Essays

Altogether 390 English essays were collected, with two removed from the final analysis due to the incompleteness of the essays. Therefore, 388 essays were included in the final analysis. Four elements based on the adapted Toulmin's (2003) model of the argument structure are examined: claim, data, counterargument and rebuttal. The number of elements was marked in each essay, and then the average were computed. The results were presented in Table2.These elements represent the argument-counterargument structure because an essay containing these features usually present not only the writer's claim and data but also readers' possible opposing views as imagined by the writer for the purpose of substantiating his/her main argument. It should be pointed out that almost all essay had one claim and at least two pieces of data; however, not every essay had counterargument and rebuttal because the average numbers for these two elements were less than 1. A detailed examination of these 388 essays demonstrated that five failed to present claims or data. On the contrary, the remaining 383 essays had one claim and relevant data. This finding shows that the majority of the participants grasped the basic elements of an argumentative essay, which coincides with Crammond (1998) who found that basic argument structure was the predominant organization structure for English-speaking students at Grade 6, Grade 8 and Grade 10.

Table 2. Descriptive statistics of the use of Toulmin elements in students' English essays $(\mathrm{n}=388)$

\begin{tabular}{|l|l|l|}
\hline Toulmin elements & Mean & SD \\
\hline Claim & .99 & .113 \\
\hline data & 2.68 & .951 \\
\hline counterargument & .62 & .685 \\
\hline rebuttal & .63 & .715 \\
\hline
\end{tabular}

As noted by Toulmin et al. (1979), counterarguments and rebuttals are of a secondary nature, it is understandable that compared to the two basic elements of an argumentative essay, namely, claim and data, fewer essays presented the secondary Toulmin elements (Crammond, 1998; McCann, 1989). Their uses are often optional and depend on the complexity of argument structures. Both Crammond (1998) and McCann (1989) argued that uses of these secondary Toulmin elements were often associated with expert writers or students of higher grades. Similarly, Perkins et al. (1991) found that even high school and college students in L1 contexts tended not to include any counterarguments. The present study, however, found that half of the participants had the tendency of presenting counterarguments; 197 of 388 essays included some form of counterarguments and 199 essays had rebuttals. In other words, Counterargument appeared in 50\% of English essays and rebuttals appeared 51\%. The results 
showed that half of the English essays composed by the participants were one-sided: the students seemed to focus only on how to state their main claim and to provide data. This might also indicate these students' lack of understanding about the value of argument-counterargument structure in making their essays more persuasive.

3.2 The Relationship between the Presence of Argument-counterargument Features and the Students' Overall Writing Quality assessed by AWE program

The second research question attempts to discover whether the presence of counterargument in the English essays could predict essay quality. As shown in Table 2, the mean score of the counterargument and rebuttal were low compared to the other two features. This suggests that a small number of students supplied these features in their essays. The overall quality of the participants' argumentative essays in English was assessed based on a 100-point scale by a Chinese AWE program, from 69 (the lowest) to 93(the highest). The scores for overall quality of the argumentative essays were normally distributed, with a mean of 83.41 and standard deviation of 4.26, as seen in Table 3. Then, four bivariate correlations were conducted to examined the statistical relationship between the use of the four Toulmin elements and the overall quality of English argumentative essays. The correlational analysis found that the overall quality of English argumentative essays were not correlated with fundamental elements, claim and data, but was positively correlated with the uses of counterargument and rebuttal, as presented in Table 4.

Table 3. Descriptive statistics of overall quality of English essays $(\mathrm{N}=388)$.

\begin{tabular}{|l|l|l|l|l|}
\hline & Mean & SD & Min. & Max. \\
\hline Over quality of English essays & 83.41 & 4.26 & 69 & 93 \\
\hline
\end{tabular}

Table 4. Pearson correlations between the use of Toulmin elements and overall quality of English argumentative essays $(\mathrm{N}=388)$

\begin{tabular}{|l|l|l|l|l|}
\hline & Claim & Data & Counterargument & Rebuttal \\
\hline $\begin{array}{l}\text { Overall quality of English argumentative } \\
\text { essays }\end{array}$ & .086 & .085 & $.121^{*}$ & $.152^{* *}$ \\
\hline
\end{tabular}

${ }^{*} P<.05 ; * * P<.01$.

It should be noted that although a significant correlation between the argument-counterargument features and the overall quality of argumentative essays was found in the present study, the predicting value of the two variables was relatively small, about $12.1 \%$ and $15.2 \%$. This suggests that the general absence of the argument-counterargument structure in the participants' English essays was also affected by other factors. One explanation is that the students might not be aware of the importance of supplying this structure to make their essays more persuasive. The 
argument-counterargument structure might not be given proper attention to in their EFL writing instruction. Liu and Stapleton (2014) argues that argumentative writing instruction in mainland Chinese universities generally neglected the teaching of counterargument and rebuttal. Liu (2005) notes that in contrast to American writing textbooks, Chinese writing textbooks do not treat "anticipating the opposite side" as a crucial element in argumentative essays. Therefore, it might be possible that the tendency of not presenting counterargument in EFL writings was because the students had not received explicit or adequate instruction as to how to develop an argument-counterargument structure. Some researchers (You, 2010; You \& Liu, 2009) suggest that in Chinese exam essays, the writer assumes the role of an authoritative person imparting knowledge and educating people, which mitigates a writer's need to persuade readers by using all argumentative elements available. With the respect to the relationship between the presence of argument-counterargument features and the students' overall writing quality, generally the use of Toulmin elements explained the overall essay quality. As the claim and data might be evaluated by AWE based on vocabulary, sentence, discourse and content, AWE program could not assess the argument-counterargument features.

\section{Conclusion}

Argument-counterargument structure is essential in argumentative essays, yet there is little research exploring this notion in Chinese students' argumentative essays, nor is it presenting in the essays assessed by AWE. In this study, we found a general absence of the argument-counterargument structure from the participants' argumentative essays. It also found a significant correlation between the participants' use of structures (counterarguments and rebuttals) and the overall quality of their essays assessed by AWE. These findings suggest that explicit instruction on how to develop a multi-sided model of argumentation is required because it represents higher order thinking process. It is also proposed that argument-counterargument structure be included in the writing curriculum for mainland Chinese undergraduates.

\section{References}

Chen, C. F. E., \& W. Y. E. Cheng. (2008). Beyond the design of automated writing evaluation: pedagogical practices and perceived learning effectiveness in EFL writing classes. Language learning \& Technology, 12(2), 94-112.

Crammond, J. (1998). The uses and complexity of argument structures in expert and student persuasive writing. Written Communication, 15, 230-268. https://doi.org/10.1177/0741088398015002004

Dikli, S. (2006). An overview of automated scoring of essays. Journal of Technology, Learning, and Assessment, 5(1), 1-35.

$\mathrm{Hu}, \mathrm{X}$. W. (2015). Effects of online self-correction on EFL students' writing quality. Computer-assisted Foreign Language Education, 163, 45-49.

Inch, E. S., \& Warnick, B. (2010). Critical thinking and communication: The use of reason in 
argument ( $6^{\text {th }}$ ed.). Boston, Mass.; Hong Kong: Allyn \& Bacon.

Knudson, R. (1992). The development of written argumentation: an analysis and comparison of argumentative writing at four grade levels. Child Study Journal, 22, 167-184.

Kobayashi H, Rinnert C. (2007). Transferability of composing competence across languages: from L2 to L1. Report for Grant-in-Aid for Scientific Research, Research Code 16520343. Available at: Hiroshima University Institutional Repository website: http://ir.lib.hiroshima-u.ac.jp/metadb/up/kaken/16520343.pdf

Leitao, S. (2003). Evaluating and selecting counterarguments. Written Communication, 20, 269-306. https://doi.org/10.1177/0741088303257507

Liao, H.C. (2016). Using automated writing evaluation to reduce grammar errors in writing. ELT Journal, 70(3), 308-319. http://dx.doi.org/10.1093/elt/ccvo58

Liu, F.L., \& Stapleton, P. (2014). Counterargumentation and the cultivation of critical thinking in argumentative writing: Investigating washback from a high-stakes test. System, 45, 117-128. https://doi.org/10.1016/j.system.2014.05.005

Liu, L. (2005). Rhetorical education through instruction across cultures: a comparative analysis of select online instructional materials on argumentative writing. Journal of Second Language Writing, 14, 1-18. https://doi.org/10.1016/j.jslw.2004.11.001

McCann, T. (1989). Student argumentative writing knowledge and ability at three grade levels. Research in the Teaching of English, 23, 62-76.

Nussbaum, E.M., \& Kardash, C.A.M., (2005). The effects of goal instruction and text on the generation of counterarguments during writing. Journal of Educational Psychology, 97, 157-169. https://doi.org/10.1037/0022-0663.97.2.157

Perkins, D., Farady, M., \& Bushey, B. (1991). Everyday reasoning and the roots of intelligence. In: Voss, J.F., Perkins, D.N., Segal, J.W. (Eds), Informational Reasoning and Education. Erlbaum, Hillsdale, NJ, pp.83-106.

Qin, J.J., \& Karabacak, E. (2010). The analysis of Toulmin elements in Chinese EFL university argumentative writing. System, 38, 444-456. https://doi.org/10.1016/j.system.2010.06.012

Ramage, J., \& Bean, C. (1999). Writing Arguments. Allyn and Bacon, Boston.

Shermis, M. D., \& J. C. Burstein (eds.). (2003). Automated Essay Scoring: A Cross-disciplinary Perspective. Hillsdale, NJ: Lawrence Erlbaum Associates.

Stapleton, P. (2001). Assessing critical thinking in the writing of Japanese university students: Insights about assumptions and content familiarity. Written Communication, 18, 506-548. https://doi.org/10.1177/0741088301018004004

Toulmin, S. (1958). The Uses of Argument. Cambridge University Press, Cambridge.

Toulmin, S. (2003). The Uses of Argument, updated ed. Cambridge University Press, 
Cambridge.

Toulmin, S., Rieke, R., \& Janik, A. (1979). An Introduction to Reasoning. Macmillan, New York.

You, X. (2010). Writing in the devil's tongue: A history of English composition in China. Carbondale, IL: Southern Illinois University Press.

You, X., \& Liu, Y. (2009). Confucians love to argue: policy essays in ancient China. College Composition and Communication, 60, 41-50.

\section{Appendix}

Writing prompt for English argumentative essay

Read the following paragraphs with contradicting views, and decide which side you will take. You should clearly state your opinions and support them with arguments and/or examples. You should write about 500 words.

The evening galas to be aired during the coming Spring Festival on national and regional TV stations are now drawing the attention of Chinese audiences. Many netizens commented that last year's galas, from the China Central Television (CCTV) to local stations, went international. French film star Sophie Marceau and South Korean actor and singer Lee Min-ho were invited as guest performers to the CCTV's Spring Festival Gala on New Year's Eve, sparking a public controversy.

Some people are excited about such famous foreign figures coming to China, and think that there is nothing wrong in inviting foreign stars to the Spring Festival evening galas, especially because a huge number of Chinese really do enjoy foreign celebrities, foreign music and exotic fashions since China started its reform and opening-up more than three decades ago.

Some people, however, say it costs a lot more to invite foreign stars to a Chinese show. The money could be saved and used for nobler causes. They also think that a majority of the Spring Festival evening galas are put on for the grass-roots, farmers and workers for example. They ask: "Will these people be interested in foreign performers? There are plenty of stars they love here in China. Why don't we bring them onto the stage?"

\section{Copyright Disclaimer}

Copyright for this article is retained by the author(s), with first publication rights granted to the journal.

This is an open-access article distributed under the terms and conditions of the Creative Commons Attribution license (http://creativecommons.org/licenses/by/3.0/). 